\title{
Inactivation of Mycobacterium bovis ssp. caprae in high-temperature, short-term pasteurized pilot-plant milk
}

\author{
P. Hammer, ${ }^{* 1}$ E. Richter, † S. Rüsch-Gerdes, † H.-G. C. Walte, ${ }^{*}$ S. Matzen, ${ }^{*}$ and C. Kiesner* \\ *Department of Safety and Quality of Milk and Fish Products, Max Rubner-Institute, Federal Research Institute of Nutrition and Food, 24103 Kiel, \\ Germany \\ †National Reference Center for Mycobacteria, Forschungszentrum Borstel, 23845 Borstel, Germany
}

\begin{abstract}
Experiments to determine the efficacy of high temperature, short time (HTST) pasteurization of milk in terms of inactivation of pathogenic microorganisms were mainly performed between 1930 and 1960. Among the target organisms were Mycobacterium bovis and Mycobacterium tuberculosis. As a result, the Codex Alimentarius prescribes that HTST treatment of milk should lead to a significant reduction of pathogenic microorganisms during milk pasteurization. Due to the development of improved methods for the detection of survivors and of more advanced heating technology, verification of this requirement seemed to be necessary. To address recent outbreaks of tuberculosis in cattle caused by $M$. bovis ssp. caprae (M. caprae) in the southern regions of Germany, this organism was tested and compared with $M$. bovis ssp. bovis (M. bovis). Experiments were performed in a pilot plant for HTST pasteurization of milk with 3 strains of $M$. caprae and 1 strain of $M$. bovis. In preliminary trials at a fixed holding time of $25 \mathrm{~s}$, the temperature at which significant inactivation occurred was $62.5^{\circ} \mathrm{C}$ for all strains. To determine $\mathrm{D}$-values (decimal reduction times) for the inactivation kinetics, the strains were tested at 65 , 62.5 , and $60^{\circ} \mathrm{C}$ at holding times of $16.5,25$, and $35 \mathrm{~s}$. At $65^{\circ} \mathrm{C}$, the $\mathrm{D}$-values of all strains ranged from 6.8 to 7.8 $\mathrm{s}$, and at $62.5^{\circ} \mathrm{C}, \mathrm{D}$-values ranged from 14.5 to $18.1 \mathrm{~s}$. Low inactivation was observed at $60^{\circ} \mathrm{C}$. When the low slope of the inactivation curve allowed calculation of a D-value, these ranged from 40.8 to $129.9 \mathrm{~s}$. In terms of $\log _{10}$ reductions, the highest values for all strains were 4.1 to $4.9 \log$ at $65^{\circ} \mathrm{C}$, with a holding time of $35 \mathrm{~s}$. The tested strains of $M$. caprae and M. bovis showed similar low resistance to heat. Standard HTST treatment should result in a high reduction of these organisms and thus the requirements of the Codex Alimentarius for inactivation of pathogens by this process are far exceeded.
\end{abstract}

Received October 6, 2014.

Accepted November 25, 2014.

${ }^{1}$ Corresponding author: philipp.hammer@mri.bund.de
Key words: Mycobacterium caprae, milk, heat inactivation, pilot plant

\section{INTRODUCTION}

Experiments to determine the efficacy of HTST pasteurization of milk in terms of inactivation of pathogenic microorganisms were mainly performed between 1930 and 1960. Among the target organisms were Mycobacterium bovis and Mycobacterium tuberculosis. Standards for pasteurization established during that time were based on approximately 100 scientific reports, and they are still partly valid today (Stumbo, 1973; Hammer, 2004). Mycobacterium bovis ssp. caprae ( $M$. caprae) is of special significance in this concern because it was determined that one-third of human cases of $M$. bovis-associated tuberculosis cases in Germany have been caused by this organism (Kubica et al., 2003). Worldwide, 13 to $31 \%$ of zoonotic human tuberculosis cases can be attributed to $M$. caprae (Pérez-Lago et al., 2014). A strong likelihood of direct transmission from cattle to humans via consumption of raw milk was shown in Croatia (Cvetnic et al., 2007). Thus, M. caprae may be regarded as an emerging zoonotic pathogen in cattle (McDaniel et al., 2014). The Codex Alimentarius (2009) prescribes that HTST treatment of milk should lead to a reduction of pathogenic microorganisms to a level at which they do not constitute a significant hazard for human health. In detail, a reduction of at least $5 \log _{10}$-steps of Coxiella burnetii is required during a treatment at $72^{\circ} \mathrm{C}$ for $15 \mathrm{~s}$ (or at $63^{\circ} \mathrm{C}$ for $30 \mathrm{~min}$ during holder treatment). Because of the development of improved methods for the detection of survivors and of more advanced heating technologies, a verification of this requirement for the reduction of pathogenic mycobacteria seemed to be necessary.

Because of recent series of outbreaks of tuberculosis in cattle, in which 33 of 43 cases were caused by $M$. caprae in the southern regions of Germany (Ministry of Nutrition and Agriculture, 2013), this organism was tested in a pilot plant for HTST treatment of milk compared with $M$. bovis ssp. bovis (M. bovis). The aim of the study was to determine kinetic inactivation data to 
ensure that $M$. caprae is inactivated during heat treatment of milk to an extent that the requirements of the Codex Alimentarius are fulfilled.

\section{MATERIALS AND METHODS}

\section{Strains and Media}

For the experiments, 3 strains of $M$. caprae (7140/99 of human origin; 7411/06 and 9681/07 of bovine origin) and 1 strain of $M$. bovis (7540/01 of bovine origin) were chosen, all from the strain collection of the National Reference Center for Mycobacteria (Borstel, Germany).

Direct streaking onto Stonebrink medium supplemented with polymyxin B, amphotericin B, carbenicillin, trimethoprim (PACT; Heipha Dr. Müller GmbH, Eppelheim, Germany) was applied for detection and enumeration of surviving mycobacteria. In addition, for growth of inocula, modified Dubos medium (Giese et al., 1996) supplemented with polymyxin, amphotericin B, nalidixic acid, trimethoprim and azlocillin (PANTA; Becton Dickinson Diagnostics, Heidelberg, Germany) was used.

\section{Experimental Setup and Performance}

The pilot-plant pasteurizer used for the experiments has been used for similar studies, and its operation was described previously (Hammer et al., 2002, 2014; Peng et al., 2013).

Each Mycobacterium strain was tested once at 72 , $70,67.5,65,62.5$, and $60^{\circ} \mathrm{C}$ to determine the temperature at which a considerable reduction occurred using a fixed holding time of $25 \mathrm{~s}$. Experiments to determine the decimal reduction time ( $\mathbf{D}$-value) were performed in triplicate for all strains at temperatures of $65,62.5$, and $60^{\circ} \mathrm{C}$, at holding times of 35,25 , and $16.5 \mathrm{~s}$ for each temperature. Retail whole UHT milk (3.5\% fat) was inoculated with the test strains.

For inoculation of UHT milk, each Mycobacterium strain was grown for 4 wk in $3 \times 400 \mathrm{~mL}$ of modified Dubos medium at $37^{\circ} \mathrm{C}$. The bacteria were removed from the growth medium by centrifugation for $10 \mathrm{~min}$ at $14,000 \times g$, and the respective pellets were resuspended in approximately $100 \mathrm{~mL}$ of UHT milk and thoroughly mixed. This suspension was added to 28 L of UHT milk in the raw milk tank of the pilot plant and further mixed for 15 min using a magnetic stirrer. Stirring was continued during the entire heating run. Colony counts of the inoculated milk were determined by spread count on Stonebrink slant medium. For this purpose, the milk was decimally diluted in $0.85 \% \mathrm{NaCl}$ (wt/vol) up to $10^{-6}$, and 2 aliquots of $0.1 \mathrm{~mL}$ each were streaked onto 2 vials of the medium. To ensure equal distribution of colonies on the medium, slants were incubated for $1 \mathrm{wk}$ in the horizontal position until all sample fluid dried off. Only slants with colony numbers $<60$ were used for evaluation. The inoculation of UHT milk with Mycobacterium strains should result in $10^{4}$ to $10^{5} \mathrm{cfu} / \mathrm{mL}$.

After heat treatment, milk samples of $5 \mathrm{~mL}$ were collected by penetrating a rubber-stoppered sampling valve located directly after the cooling section of the pilot plant utilizing a sterile one-way syringe and needle. The sample temperature at collection was $<12^{\circ} \mathrm{C}$. Until processing (up to $1 \mathrm{~h}$ delay), the samples were stored at $4^{\circ} \mathrm{C}$ in a refrigerator.

To determine the colony counts of survivors, the heated milk samples were decimally diluted in $0.85 \%$ $\mathrm{NaCl}$ (wt/vol) to $10^{-5}$, streaked onto Stonebrink medium (see above), and incubated at $37^{\circ} \mathrm{C}$. In addition, for detection of low numbers of survivors, 5 samples of undiluted milk ( $0.2 \mathrm{~mL}$ each) were streaked onto 5 vials of the medium. After 4 and 6 wk of incubation, the slants were evaluated.

One isolate from each experiment was picked randomly to verify that tuberculosis-causing mycobacteria were detected and not a contaminating species of the genus. For this purpose, a reverse line blot assay was applied (GenoType Mycobacterium CM/AS, Hain Lifescience, Nehren, Germany).

\section{Evaluation of Data}

To determine the $\mathrm{D}$-values, a log-linear regression curve was calculated using Excel 2010 (Microsoft Corp., Redmond, WA) by plotting $\log _{10} \mathrm{~N}_{\mathrm{t}}$ (count of surviving bacteria) divided by $\log _{10} \mathrm{~N}_{0}$ (initial count) against holding time. The $\mathrm{D}$-value was calculated as the divisor of 1 and the slope of the regression curve. To analyze the fit of the model, the coefficient of determination $\left(\mathrm{R}^{2}\right)$ was calculated for each curve; D-values from triplicate experiments were averaged and the standard deviation was calculated. To determine the z-values (temperature enhancement needed for a 10 -fold reduction of the D-value), the procedure described above was applied by plotting the $\log _{10}$-transformed averaged $\mathrm{D}$-values against heating temperature.

For the statistical evaluation of the $\log$ reduction, the statistical package SAS (version 9.4; SAS Institute Inc., Cary, NC) was used. After $\log _{10}$ transformation of the bacterial counts, a variance analysis was performed. The calculation was carried out using the general linear model (GLM) procedure, which performs ANOVA by using least squares regression to fit general linear models. In the procedure, the following factors were considered for the estimation of the reduction: Mycobacterium strain, temperature, and holding time. 


\section{RESULTS AND DISCUSSION}

To our knowledge, this is the first study presenting kinetic inactivation data for $M$. caprae in milk derived from heating experiments with a pilot plant closely mimicking modern commercial systems. The aim of this experimental setup was to generate data for risk considerations in practice.

Thus, one intention was to use raw milk for the heating experiments to reflect the natural situation. However, in preliminary trials, we found that the Stonebrink medium was completely lysed during long-term incubation ( $>3$ wk) with samples containing raw milk. Most likely, this result was due to the protease plasmin, which is naturally present in milk and is inactivated in UHT milk.

From each experiment, 1 isolate of the survivors was picked randomly to verify that mycobacteria were detected and not a contaminating species of the genus. Colonies of the test strains had typical morphology on Stonebrink medium. No contaminants, neither mycobacteria nor of any other species, were detected (data not shown). As UHT milk was used for the experiments, the pilot plant was decontaminated by circulating water heated to $98^{\circ} \mathrm{C}$ for 30 min before starting the runs (Hammer et al., 2002, 2014; Peng et al., 2013), and the raw milk tank was autoclaved before use, all work was performed in a nearly sterile system (which was also necessary to meet biosafety-level 3 requirements). Therefore, the random picking was performed only as an additional safety measure to ensure that mycobacteria were present after heating.

\section{$D$ - and z-Values}

Each Mycobacterium strain was tested once at 72, 70, $67.5,65,62.5$, and $60^{\circ} \mathrm{C}$ using a fixed holding time of 25 $\mathrm{s}$ to determine the temperature at which a considerable reduction occurred. This reduction was observed at 65 and $62.5^{\circ} \mathrm{C}$. No survival was detected above $65^{\circ} \mathrm{C}$. Considering this result, $65,62.5$, and $60^{\circ} \mathrm{C}$ were selected as target temperatures for the determination of $\mathrm{D}$-values.

At $65^{\circ} \mathrm{C}$, the $\mathrm{D}$-values of all strains ranged from 6.8 to $7.8 \mathrm{~s}$, and at $62.5^{\circ} \mathrm{C}$, the $\mathrm{D}$-values were between 14.5 and $18.1 \mathrm{~s}$. Weak inactivation was observed at $60^{\circ} \mathrm{C}$. If the low slope of the inactivation curve allowed calculation of D-values, they were between 40.8 and $129.9 \mathrm{~s}$ and showed a large deviation if more than one value was obtained ( $M$. bovis $7540 / 01$; Table 1$)$. For the one

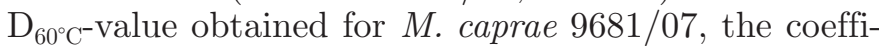
cient of determination $\left(\mathrm{R}^{2}\right)$ was $<0.7$, which indicates a weak fit with the log-linear regression model. However, the $\mathrm{z}$-value calculated for this strain showed a very strong fit $\left(\mathrm{R}^{2}=1.00\right.$; Table 1$)$. To demonstrate the quality of the $\mathrm{D}$-values in the table, the lowest $\mathrm{R}^{2}$ from the triplicate experiments is given. In total, 28 values for $\mathrm{R}^{2}$ were obtained, 18 of which were $\geq 0.9,7$ were $\geq 0.8,2$ were $\geq 0.7$, and 1 was $<0.7$, as already stated. This shows that the inactivation could, in most cases, be well described with the log-linear model.

For $M$. caprae 7140/99, no z-value could be calculated because only $2 \mathrm{D}$-values were obtained. The z-values for the other strains, including $M$. bovis, were between 4.1 and $7.1^{\circ} \mathrm{C}$ and showed a very good fit with the loglinear regression model.

Table 1. D (decimal reduction time; seconds)- and z (temperature change required for $1 \log$ reduction in D)-values for the inactivation of 3 Mycobacterium bovis ssp. caprae and 1 Mycobacterium bovis ssp. bovis strain in milk

\begin{tabular}{|c|c|c|c|c|c|c|}
\hline Strain & Temperature $\left({ }^{\circ} \mathrm{C}\right)$ & D-value ${ }^{1}$ & $\mathrm{SD}$ & $\mathrm{R}^{2}$ & z-value $\left({ }^{\circ} \mathrm{C}\right)$ & $\mathrm{R}^{2}$ \\
\hline M. caprae $9681 / 07$ & $\begin{array}{l}65 \\
62.5 \\
60\end{array}$ & $\begin{array}{r}8.1 \\
17.4 \\
40.8^{4}\end{array}$ & $\begin{array}{l}1.0 \\
2.9 \\
-\end{array}$ & $\begin{array}{l}0.79 \\
0.81 \\
0.57^{5}\end{array}$ & $7.1^{\circ} \mathrm{C}$ & 1.00 \\
\hline M. bovis $7540 / 01$ & $\begin{array}{l}65 \\
62.5 \\
60\end{array}$ & $\begin{array}{c}6.8 \\
14.5 \\
52.1^{6}\end{array}$ & $\begin{array}{r}0.1 \\
0.9 \\
22.5\end{array}$ & $\begin{array}{l}0.87 \\
0.92 \\
0.85\end{array}$ & $5.7^{\circ} \mathrm{C}$ & 0.98 \\
\hline
\end{tabular}

${ }^{1}$ The D-values are mean values of 3 independent experiments, and the lowest coefficient of determination $\left(\mathrm{R}^{2}\right)$ of the log-linear regression model used for evaluation is given.

${ }^{2}$ Not determined because only $2 \mathrm{D}$-values were available.

${ }^{3}$ No reduction.

${ }^{4}$ One value only (2 showed no reduction).

${ }^{5} \mathrm{An} \mathrm{R}^{2}<0.7$ shows a weak fit with the log-linear regression model.

${ }^{6}$ Two values ( 1 showed no reduction). 
In the scientific literature, there are few reports on the elaboration of kinetic data for the inactivation of mycobacteria as described herein. Most of the work has been performed in a purely empirical manner; for example, testing whether a certain heat treatment with defined temperature and time conditions is effective (Hammer, 2004). The monograph of Stumbo (1973)

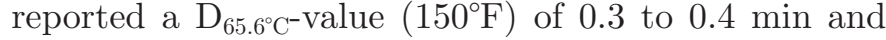
a corresponding z-value of 4.4 to $5.6^{\circ} \mathrm{C}\left(8-10^{\circ} \mathrm{F}\right)$ for M. tuberculosis. That $\mathrm{z}$-value is similar to our data, whereas the reported D-value is approximately 3 -fold higher. However, it is not apparent what equipment was used to determine the data reported by Stumbo (1973).

\section{$\log _{10}$ Reduction}

Values for $\log _{10}$ reduction were determined from direct colony counts on Stonebrink medium. If no count was obtained, the initial count was used to estimate the minimum reduction achieved, although the actual reduction could have been even higher (worst case).

According to the variance analysis, the Mycobacterium strain, temperature, and holding time all had highly significant $(P<0.001)$ effects on the reduction. The reduction increased with increasing temperature and holding time. The model explained $93 \%\left(\mathrm{R}^{2}\right)$ of the total variance, which was $86 \%$ for the temperature, $6 \%$ for the holding time, and $1 \%$ for the strain. In Table 2 , additive constants in $\log _{10}$ for the tested factors are summarized.

Among the possible interactions, only the interaction temperature $\times$ holding time was significant $(P<0.001)$. The interaction explained an additional $1 \%$ of the variance; thus, there was only a slight increase $(94 \%)$ of the explained variance through the model. The estimated least squares means did not change; only the standard errors were slightly reduced (data not shown).

A box-and-whisker plot (Figure 1) shows the dependence of the $\log _{10}$ reduction on temperature and hold- ing time for all strains using the raw data. This result highlights the strong dependence of the inactivation on temperature. As the strains contributed only $1 \%$ to the explanation of variance, they were not regarded separately in the graph. The whiskers display the lowest and highest values within $1.5 \times$ interquartile range (25th-75th percentile) and the dots outside this range are suspected outliers.

The averaged highest values for $\log _{10}$ reduction of all strains were between 4.1 and $4.9 \log _{10}$ at $65^{\circ} \mathrm{C}$ and a holding time $35 \mathrm{~s}$. At $25 \mathrm{~s}$, the averaged highest values were 3.7 to $4.9 \log _{10}$, and at $16.5 \mathrm{~s}$, they were 2.3 to $3.9 \log _{10}$. This result shows that a reduction of more than $2 \log _{10}$ could be achieved at a holding time of $16.5 \mathrm{~s}$ at $65^{\circ} \mathrm{C}$, which is also reflected in the D-values of 6.8 to $8.1 \mathrm{~s}$ determined for all strains. Regarding the requirement of the Codex Alimentarius (2009) that pathogens should be reduced by at least $5 \log _{10}$ during HTST treatment for $15 \mathrm{~s}$ at $72^{\circ} \mathrm{C}$, a reduction of $>18$ log-cycles can be extrapolated from the present data. In a worst-case scenario for all strains, this can be calculated as follows: Adding the highest determined z-value $\left(7.1^{\circ} \mathrm{C}\right)$ to $65^{\circ} \mathrm{C}$ would reduce the highest measured Dvalue $(8.1 \mathrm{~s})$ by a factor of 10 , to $0.81 \mathrm{~s}$. Dividing the target holding time of $15 \mathrm{~s}$ for HTST by $0.81 \mathrm{~s}$ results in the value of $>18$ log-cycles given above.

Compared with those for $M$. caprae, recent data for M. avium ssp. paratuberculosis are available that clearly indicate that this organism is more heat resistant: $M$. paratuberculosis showed survival of small numbers at HTST conditions (Grant et al., 2002; Hammer et al., 2002, 2014; McDonald et al., 2005; Van Brandt et al., 2011). In their quantitative risk assessment on the survival of $M$. paratuberculosis in 3 milk pasteurization plants in Italy, Serraino et al. (2014) proposed a 4- to 7-log reduction based on the results from industrialscale experiments. As results for inactivation of $M$. paratuberculosis achieved with our pilot plant meet this proposal very well (Hammer et al., 2002, 2014), we estimate that the inactivation data obtained for $M$. caprae

Table 2. Variance analysis: additive constants (in $\log _{10}$ ) for factors and their influence on the reduction of Mycobacterium spp. (overall mean $\mu=-4.409$ )

\begin{tabular}{|c|c|c|c|c|}
\hline Factor & Level & Constant & LSM & $\mathrm{SE}$ \\
\hline \multirow[t]{4}{*}{ Strain } & M. caprae $7140 / 99$ & 0.212 & $-1.655^{\mathrm{a}}$ & 0.092 \\
\hline & M. caprae $7411 / 06$ & 0.314 & $-1.553^{\mathrm{a}}$ & 0.092 \\
\hline & M. caprae $9681 / 07$ & 0.000 & $-1.867^{\mathrm{ab}}$ & 0.092 \\
\hline & M. bovis $7540 / 01$ & -0.218 & $-2.085^{\mathrm{b}}$ & 0.092 \\
\hline \multirow{3}{*}{ Temperature $\left({ }^{\circ} \mathrm{C}\right)$} & 60 & 3.848 & $-0.012^{\mathrm{a}}$ & 0.079 \\
\hline & 62.5 & 2.361 & $-1.498^{b}$ & 0.079 \\
\hline & 65 & 0.000 & $-3.860^{\mathrm{c}}$ & 0.079 \\
\hline \multirow[t]{3}{*}{ Holding time (s) } & 15 & 1.012 & $-1.251^{\mathrm{a}}$ & 0.079 \\
\hline & 20 & 0.406 & $-1.857^{\mathrm{b}}$ & 0.079 \\
\hline & 25 & 0.000 & $-2.263^{\mathrm{c}}$ & 0.079 \\
\hline
\end{tabular}

${ }^{\mathrm{a}-\mathrm{C}}$ Values with different superscripts within the same factor show significant differences $(P<0.05)$. 


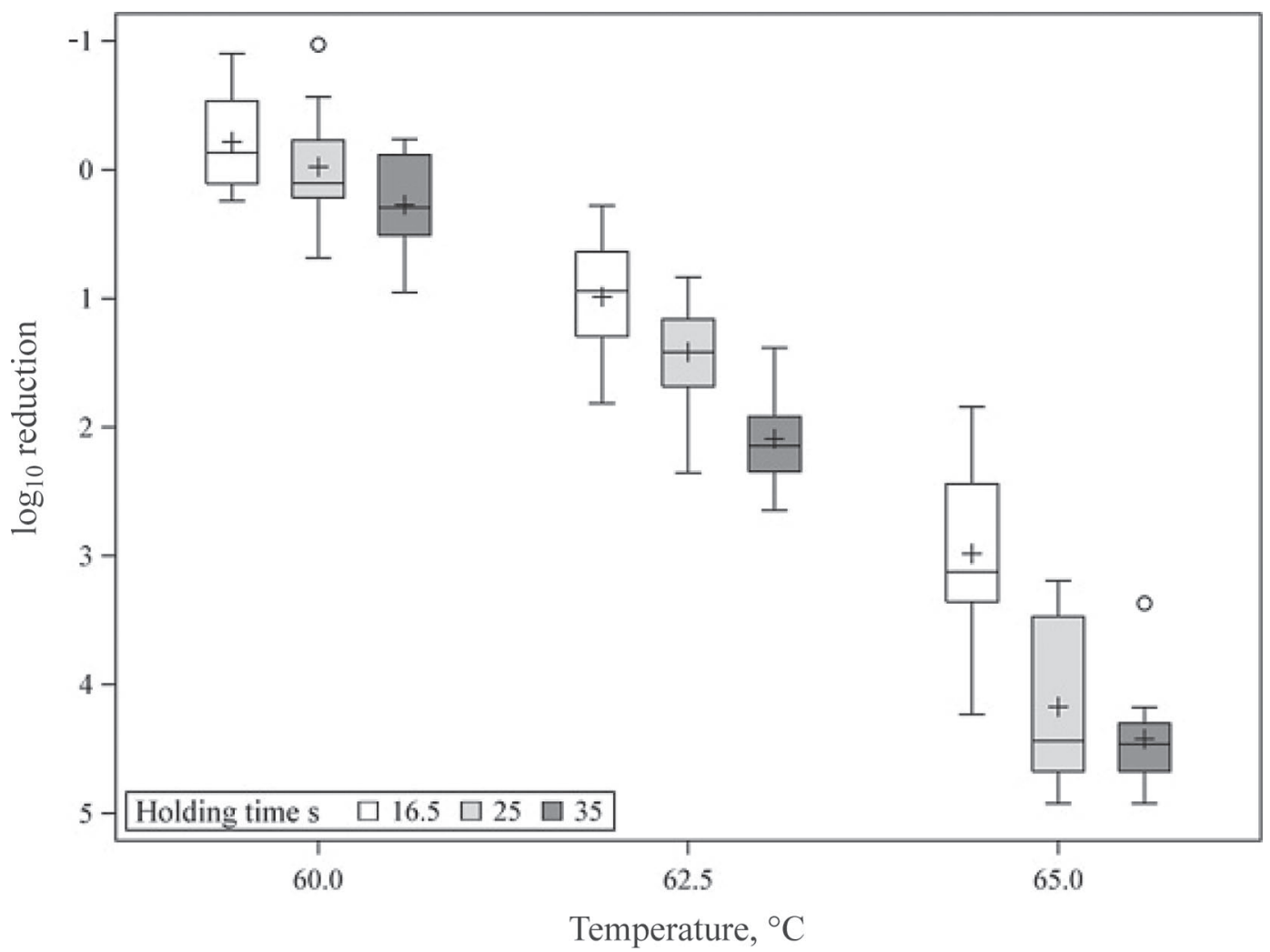

Figure 1. Box-and-whisker plot of the dependence of the $\log _{10}$ reduction on temperature and holding time for all strains included. The upper margin of the box shows the 75th percentile, the lower margin the 25th percentile, the line in the box the median value, and the cube the mean value. The whiskers display the lowest and highest values within $1.5 \times$ interquartile range $(25$ th- 75 th percentile). The dots outside this range are suspected outliers.

with this equipment reflect the situation in practice. The high initial count in our experiments represents a worst-case situation; however, it allowed us to gain measured values at the chosen temperatures. Regarding the extrapolation example given above, it would be rather unlikely that, under HTST conditions, any measured value could be obtained.

Presently, no data are published on the natural occurrence of $M$. caprae in milk of infected animals. Such data are needed for proper exposure assessment in the framework of risk assessment (Codex Alimentarius, 1999). In addition, it might be necessary to expand the database of inactivation results by further tests with strains of caprine origin. It will be necessary to elaborate an international database with comparable results, harmonization of testing equipment, detection methods for survivors, number of organisms to be tested, and adaptation of these to the heating menstruum (Condron et al., 2015).

\section{CONCLUSIONS}

The tested strains of $M$. caprae and $M$. bovis showed similar low resistance to heat. The standard HTST treatment should result in substantial reduction of the organisms and thus will far exceed the requirements of the Codex Alimentarius for inactivation of pathogens by this process. Even at the subpasteurization temperature of $65^{\circ} \mathrm{C}$, a reduction of at least $4 \log _{10}$ can be achieved during continuous flow treatment for $35 \mathrm{~s}$.

\section{ACKNOWLEDGMENTS}

The authors thank Susanne Cochoy and Svenja Feuerhahn (Max Rubner-Institute, Department of Safety and Quality of Milk and Fish Products, Kiel, Germany), and Ilse Radzio (National Reference Center for Mycobacteria, Forschungszentrum Borstel, Borstel, Germany) for excellent technical assistance.

\section{REFERENCES}

Codex Alimentarius. 1999. Principles and guidelines for the conduct of microbiological risk assessment. CAC/GP 30-1999. Codex Alimentarius Commission, Rome, Italy.

Codex Alimentarius. 2009. Code of hygienic practice for milk and milk products. CAC/RCP 57-2004. 2nd ed. Codex Alimentarius Commission, Rome, Italy.

Condron, R., C. Farrokh, K. Jordan, P. McClure, T. Ross, and O. Cerf. 2015. Guidelines for experimental design protocol and valida- 
tion procedure for the measurement of heat resistance of microorganisms in milk. Int. J. Food Microbiol. 192:20-25.

Cvetnic, Z., V. Katalinic-Jankovic, B. Sostaric, S. Spicic, M. Obrovac, S. Marjanovic, M. Benic, B. K. Kirin, and I. Vickovic. 2007. Mycobacterium caprae in cattle and humans in Croatia. Int. J. Tuberc. Lung Dis. 11:652-658.

Giese, S. B., A. Huda, A. Wedderkopp, J. Klausen, and P. Ahrens. 1996. Cultivation of Mycobacterium paratuberculosis in Dubos broth combined with PCR. Pages 302-306 in Proc. Fifth Int. Colloq. Paratuberculosis, Madison, WI. International Association for Paratuberculosis, Rehoboth, MA.

Grant, I. R., E. I. Hitchins, A. McCartney, F. Ferguson, and M. T. Rowe. 2002. Effect of commercial-scale high-temperature, shorttime pasteurization on the viability of Mycobacterium paratuberculosis in naturally infected cows' milk. Appl. Environ. Microbiol. 68:602-607.

Hammer, P. 2004. Heat resistance of classical Mycobacteria-A historical review. IDF Bull. 392:42-48.

Hammer, P., C. Kiesner, H.-G. Walte, K. Knappstein, and P. Teufel. 2002. Heat resistance of Mycobacterium avium ssp. paratuberculosis in raw milk tested in a pilot plant pasteurizer. Kieler Milchwirtsch. Forschungs. 54:275-303.

Hammer, P., C. Kiesner, and H.-G. C. Walte. 2014. Short communication: Impact of homogenization on heat inactivation of $M y$ cobacterium avium ssp. paratuberculosis in milk. J. Dairy Sci. 97:2045-2048.

Kubica, T., S. Rüsch-Gerdes, and S. Niemann. 2003. Mycobacterium bovis subsp. caprae caused one-third of human M. bovis-associated tuberculosis cases reported in Germany between 1999 and 2001. J. Clin. Microbiol. 41:3070-3077.
McDaniel, C. J., D. M. Cardwell, R. B. Moeller Jr., and G. C. Gray. 2014. Humans and cattle: A review of bovine zoonoses. VectorBorne Zoonot. Dis. 14:1-19.

McDonald, W. L., K. J. O'Riley, C. J. Schroen, and R. J. Condron. 2005. Heat inactivation of Mycobacterium avium ssp. paratuberculosis in milk. Appl. Environ. Microbiol. 71:1785-1789.

Ministry of Nutrition and Agriculture. 2013. Official Monthly Animal Health Report of Ministry of Nutrition and Agriculture of Germany. Accessed Mar. 13, 2014. tsis.fli.bund.de/Reports/ AnimalHealth.aspx.

Peng, S., J. Hummerjohann, R. Stephan, and P. Hammer. 2013. Short communication: Heat inactivation of pathogenic and non-pathogenic Escherichia coli in raw milk at subpasteurization temperatures tested in a pilot plant pasteurizer. J. Dairy Sci. 96:35433546.

Pérez-Lago, L., Y. Navarro, and D. García-de-Viedma. 2014. Current knowledge and pending challenges in zoonosis caused by Mycobacterium bovis: A review. Res. Vet. Sci. 97(Suppl.):S94-S100.

Serraino, A., P. Bonilauri, N. Arrigoni, F. Ostanello, M. Ricchi, G. Marchetti, E. Bonfante, S. Albonetti, and F. Giacometti. 2014. Quantitative risk assessment of Mycobacterium avium ssp. paratuberculosis survival in pasteurized milk in three dairy plants in Italy. Food Contr. 45:120-126.

Stumbo, C. R. 1973. Thermobacteriology in Food Processing. 2nd ed. Academic Press New York, NY.

Van Brandt, L., I. Van der Plancken, J. De Block, G. Vlaemynck, E. Van Coillie, L. Herman, and M. Hendrickx. 2011. Adequacy of current pasteurization standards to inactivate Mycobacterium paratuberculosis in milk and phosphate buffer. Int. Dairy J. 21:295-304. 